\title{
Hesio Cordeiro: \\ uma justa homenagem
}

\section{$I^{1}$ Gulnar Azevedo e Silva I}

${ }^{1}$ Instituto de Medicina Social, Universidade do Estado do Rio de Janeiro. Rio de Janeiro-RJ, Brasil (gulnar@ims.uerj.br). ORCID: 0000-0001-8734-2799

DOI: http://dx.doi.org/10.1590/S0103-73312021310300

Em 2004 foi publicado na Physis o artigo de Hesio Cordeiro intitulado "O Instituto de Medicina Social e a Luta pela Reforma Sanitária: Contribuição à História do SUS" (CORDEIRO, 2004). Nesse artigo, escrito 16 anos após o direito à saúde se tornar cláusula pétrea da Constituição Federal de 1988, Hesio termina propondo dez pontos nos quai o Instituto de Medicina Social (IMS) da UERJ e as instituiçóes de ensino e pesquisa em Saúde Coletiva poderiam contribuir para a produção de conhecimento associado à formação e às práticas inovadoras para assegurar qualidade e equidade. Entre esses pontos, merecem destaque: "reconsiderar as normas do SUS à luz das necessidades dos cidadãos e cidadãs, tornando-as ágeis e mais simples para evitar a hipertrofia tecnoburocrática de um Estado cujas relaçóes sociais e técnicas se orientam pelo segredo e pela pouca transparência, além da fragmentação dos interesses dos grupos e classes sociais" e "dar contribuição para elaborar um projeto de ciência e tecnologia em saúde, envolvendo a gestão, o uso de novos procedimentos, insumos e métodos baseados em evidências científicas e resultados". Essas duas recomendaçóes de Hesio não perderam o seu valor e agora, e mais do que nunca, seguem vivas e deixam um recado claro para todos nós que dedicamos nossas vidas à saúde coletiva. 
Neste número que é lançado 17 anos após o artigo de 2004, a Physis publica o Dossiê Hesio Cordeiro com comentários que mostram o vigor e a criatividade de nosso mestre por onde ele passou. Resgatam com muita verdade e delicadeza o legado de Hesio, não só pelo que ele nos ensinou, mas também pelo que construiu, como pode ser observado na breve cronologia ${ }^{1}$ apresentada ao final deste editorial.

Os depoimentos aqui presentes realçam a trajetória de Hesio nos diversos espaços em que atuou. Deixam bem marcados seu investimento na formação de profissionais críticos e comprometidos com o desenvolvimento do país, assim como seus passos firmes para garantir o acesso à saúde com qualidade para toda a população.

O conhecido artigo "A questão democrática e a saúde", de Hesio Cordeiro, José Luís Fiori e Reinaldo Guimarães, aqui republicado, foi escrito em 1976 e publicado em 1980 pela Revista do CEBES (CORDEIRO; FIORI; GUIMARÁES, 1980). Esse texto se transformou em um "verdadeiro manifesto do movimento sanitário brasileiro", como afirma Fiori em seu texto de apresentação, também incluído neste número. Foi a partir desse texto de 1976 que Hesio e colaboradores contribuíram publicamente com uma reflexão que serviu de base para os trabalhos da VIII Conferência Nacional de Saúde em 1986.

Guimarães, em seu comentário, descreve de forma detalhada o papel decisivo de Hesio na criação do Instituto de Medicina Social da UERJ no final dos anos 1960. Foi em plena ditatura militar que Hesio e outros dois médicos formados pela Faculdade de d Ciências Médicas (FCM) da UERJ, Nina Pereira Nunes e Moysés Szklo, com apoio de Piquet Carneiro, titular de clínica médica da FCM, colocaram em prática um projeto ambicioso para a época. Como mostra Fiori, o Instituto foi capaz de trazer questôes sociais para dentro de uma Faculdade de Medicina, oferecendo aos alunos formação teórica e crítica política.

Ao mesmo tempo em que se dedicava à estruturação do IMS, Hesio não cuidou apenas de seu trabalho como professor e pesquisador, mas dividiu seu tempo como um ativista para a garantia do direito à saúde. Este aspecto fica bem claro no artigo de Rodrigues, que resgata a importância de Hesio na orientação da Política Nacional de Saúde, relatando sua participação no I Simpósio sobre Política Nacional de Saúde da Câmara de Deputados em 1979.

Com muita ênfase, Noronha, Temporão e Sayd, em seus comentários (que no caso de Sayd tomam os contornos de uma resenha), traçam a importância de Hesio na construção do Sistema Único de Saúde (SUS) e como teórico da reforma sanitária 
brasileira. Seguindo a trajetória de Hesio como mestre, Moraes descreve em seu depoimento a importância que ele teve na formação de gerações de sanitaristas, inovando conteúdos em cursos de graduação e de pós-graduação.

Com a dupla missão de gestor e professor, Hesio sempre se preocupou em avançar o conhecimento na área de saúde, mantendo seu olhar atento para o coletivo e o indivíduo. É esta a marca que o IMS mantém até hoje. Não há dúvida de que isto foi possível por ser Hesio uma pessoa tão especial que escutava e acolhia todos, como descreve Rodrigues dos Santos em seu depoimento que trata do legado humanista e civilizatório de Hesio.

Muito nos orgulha a nomeação do IMS como Instituto de Medicina Social Hesio Cordeiro. Nosso homenageado merece o título dado por Temporão: um gigante da Saúde Coletiva!

\section{Referências}

CORDEIRO, H. A. O Instituto de Medicina Social e a Luta pela Reforma Sanitária: Contribuição à História do SUS. Physis: Revista de Saúde Coletiva, v. 14, n. 2, p. 343-362, 2004.

CORDEIRO, H. A.; FIORI, J. L.; GUIMARĀES, R. A questão democrática e a saúde. Saúde em Debate, n. 9, 1980.

\begin{tabular}{|l|l|}
\hline Período/ano & Fato \\
\hline 1942 & Nasce em Juiz de Fora \\
\hline $1960-1965$ & UEG/UERJ - Formaçáo em Medicina \\
\hline $1966-1967$ & Residência em Clínica Médica na UERJ \\
\hline $1967-1971$ & Médico na UERJ \\
\hline 1970 & Um dos fundadores do IMS \\
\hline $1971-1978$ & $\begin{array}{l}\text { Consultor da OPAS (Argentina, Peru, Equador, Venezuela, Costa Rica, Nicarágua, } \\
\text { Hounduras, México e República Dominicana) }\end{array}$ \\
\hline 1971 & Docente do IMS \\
\hline 1974 & Criaçáo do Programa de Pós-Graduação do IMS \\
\hline 1977 & "A Questáo Democrática e a Saúde" (Hesio, Fiori e Reinaldo) \\
\hline 1978 & Mestre em Saúde Coletiva pelo IMS; orientadora: Maria Andrea Loyola Leblond \\
\hline 1979 & I Simpósio sobre Saúde na Câmara dos Deputados \\
\hline
\end{tabular}




\begin{tabular}{|c|c|}
\hline $1979-1981$ & $\begin{array}{l}\text { Doutor em Medicina Preventiva pela Faculdade de Medicina da USP, orientadora: } \\
\text { Maria Cecília Ferro Donnangelo }\end{array}$ \\
\hline 1980 & Publica o livro A Indústria da Saúde no Brasil, pela editora Graal \\
\hline 1981 & $\begin{array}{l}\text { Publica o livro La pratica Médica em America Latina pela Universidade Autônoma de } \\
\text { Santo Domingo, em coautoria com H. Mercer. }\end{array}$ \\
\hline $1983-1985$ & Presidente da Abrasco \\
\hline $1983-1984$ & Diretor do IMS \\
\hline 1984 & $\begin{array}{l}\text { Publica o livro Empresas Médicas: as transformaçôes capitalistas da prática médica pela } \\
\text { Editora Graal }\end{array}$ \\
\hline $1985-1988$ & Presidente do INAMPS \\
\hline 1986 & Membro da Comissão Organizadora da 8a Conferência Nacional de Saúde \\
\hline 1988 & Doutor honoris causa pela ENSP \\
\hline 1990 & Candidato a deputado federal pelo PDT \\
\hline 1991 & Publica o livro Sistema Único de Saúde pela Ayuri Ed./ABRASCO \\
\hline $1992-1996$ & Reitor da UERJ \\
\hline 1993-1995 & Presidente da Associação Brasileira das Universidades Estaduais e Municipais - ABRUEM \\
\hline 1996 a 2011 & Consultor da Fundação Cesgranrio - coordenador de saúde \\
\hline 1996 a 1997 & Conselheiro do Conselho Nacional de Educação (CNE) \\
\hline 1996 & Aposenta-se do IMS/UERJ \\
\hline 1997 a 1999 & Presidiu o Conselho Nacional de Educação (CNE) \\
\hline 1999 & Secretário de Educação do Estado do Rio de Janeiro \\
\hline $2000-2006$ & Coordenou o curso de Medicina da Universidade Estácio de Sá \\
\hline $2003-2005$ & Criou o $1^{\circ}$ Programa de Pós-Graduação em Saúde da Família da Universidade de Sá \\
\hline $2005-2015$ & Coordenou o Mestrado Profissional em Saúde da Família da Universidade Estácio de Sá \\
\hline 2005 & Publica a $2^{a}$ edição do livro Sistema Único de Saúde pela Editora Rio \\
\hline $2007-2010$ & Diretor de gestão da ANS \\
\hline 2007 & Medalha do Mérito de Oswaldo Cruz- categoria ouro, Ministério da Saúde \\
\hline 2009 & $\begin{array}{l}\text { Título de Cidadão do Estado do Rio de Janeiro, Assembleia Legislativa do Estado do } \\
\text { Rio de Janeiro projeto de Resoluçấo 1105/2009. }\end{array}$ \\
\hline 2011 & Comenda Sergio Arouca, Conselho Federal de Medicina. \\
\hline 2014 & Recebe o título de Doutor honoris causa pela Fiocruz \\
\hline $2020 /$ nov & Falecimento \\
\hline
\end{tabular}




\section{Nota}

${ }^{1} \mathrm{O}$ quadro cronológico aqui apresentado foi elaborado com base em informaçôes retiradas de: <http:// cebes.org.br/2020/11/homenagens-do-cebes-a-hesio-cordeiro-um-dos-idealizadores-e-construtores-do-sus/>; <https://periodicos.fiocruz.br/pt-br/content/hesio-cordeiro-e-sa\%C3\%BAde-coletiva-uma-homenagem-sua-trajet $\% \mathrm{C} 3 \% \mathrm{~B} 3$ ria- $0>;<\mathrm{Cv}$ Lattes Hesio de Albuquerque Cordeiro $>$ e $<$ https://cee.fiocruz. $\mathrm{br} /$ ?q=node/1276>. 